\title{
8 Linking semantics to syntax
}

In this chapter, I go into 1) linking the LS to the morphosyntax and the coding strategies, 2) the expansion of base logical structures to accommodate instruments, causees, comitatives and implements and 3) several constructions containing instruments. With respect to 3), recall from the introduction that instruments occur in a wide variety of morphosyntactic configurations. Consider:

(1) a. Todd shattered the window with the rock.

b. The rock shattered the window. (ISA, see chapter 6)

c. The window was shattered by Todd with the rock.

d. The window was shattered by the rock.

e. The window shattered with the rock. ${ }^{1}$

f. The window shatters easily with a rock.

I refer to the typical examples featuring instruments that I have employed throughout this dissertation as the standard instrument example. It includes examples like the ones in (2).

(2) a. Fohn cut down the tree with an axe.

b. Sarah opened the box with the knife.

Parallel to the standard occurrence of instruments, there is a standard implement example. To date, no language has been found that morphologically distinguishes between implements and instruments. Both classes of tools do show syntactic differences in different languages, however. Implements can never undergo ISA and in languages where it is very productive, like English, this becomes immediately visible. The linking of

1 This sentence is rejected by many native speakers and it does not fit naturally in RRG. Because it occurs in the relevant literature, sentences of this type have been included in this chapter. 
both standard implements and standard instruments will be explored in the general linking sections (8.1 and 8.2). Special constructions featuring instruments and/or implements will be discussed in sections 8.3 onwards.

\subsection{Three classes of prepositions}

RRG makes a distinction between predicative and non-predicative prepositions (Van Valin 2005: 21ff.). In contrast to the former, the latter mark arguments in the core and have a flat syntactic structure. Predicative prepositions introduce new semantic content and license an argument. Jolly (1993: 286) argues in favor of recognizing a category in between, the semi-predicative prepositions (class two-prepositions). These prepositions are said to introduce a new argument to the larger LS. A crucial feature of class two-prepositions is argument-sharing: The added section of LS has to share an argument with the base LS. Van Valin \& LaPolla 1997: 159-160) call these argument-adjunct prepositions. Syntactically, these PPs take the form of predicative PPs, but they occur in the core. Prime examples of this kind are PPs involved in the alternation between activities and active accomplishments. Consider (adapted from Van Valin \& LaPolla 1997: 160):
a. Paul ran.
b. do' (Paul, [run' (Paul)])
c. Paul ran to the store.
d. do' (Paul, [run' (Paul)]) \& INGR be-at' (store, Paul) ${ }^{2}$

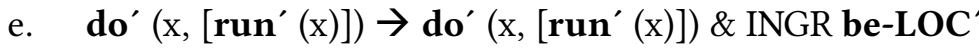 $(y, x)$

In the examples above, to has its own logical structure that is added to the base LS by means of a lexical rule (Van Valin 2013: 85) given in (3e).

2 The analysis of active accomplishments has changed over time due to updates in theory. In Van Valin \& LaPolla (1997) BECOME is used in the LS, whereas in Van Valin (2005), INGR is used instead. The notation in (3) follows the theory as outlined in Van Valin (2005). 
As this example involves argument sharing, it can be considered an argument-adjunct preposition.

Whenever a preposition is considered to be non-predicative, the corresponding PP in the syntax has the typical flat structure. If the preposition is considered to be class 2, then the PP will be predicative but occur in the core.

\subsection{Argument linking in Role and Reference Grammar}

Linking the logical structures to their morphosyntactic expression is handled in terms of the linking algorithm (see section 2.5.3) in RRG. In the following sections, I will primarily explore argument linking and marking in English, French, Dutch and German. The notions of macroroles are crucial in this regard as RRG does not use traditional notions like subject, object and indirect object to this end. The rules for assigning the macroroles to components of the LS were given in (2.5.1). Of these four languages, only German has a case system. The other three use prepositional marking to a large extent. ${ }^{3}$ I use English as a preliminary reference point for the coming sections. In English, prepositions are used to mark some core arguments. The preposition with is particularly interesting for two reasons: 1) It is the main marker for instruments, and thus of the utmost importance for this study and 2) it has a wide array of functions beyond instrument marking (Van Valin \& LaPolla 1997: 376ff., Jolly 1993). This last point is illustrated by the occurrence of multiple with-PPs in a sentence. Consider the English example in (5a) (Van Valin \& LaPolla 1997: 377) and its direct Dutch equivalent in (5b).

(4) a. The woman with strong arms loaded the truck with hay with a pitchfork with Bill with enthusiasm.

b. De vrouw met sterke armen belaadde de vrachtwagen met hooi met een hooivork met Bill met enthousiasme.

3 It is important to point out that PP-internal cases, assigned by governing prepositions are not covered by these rules (Van Valin \& LaPolla 1997: 359). 
RRG assumes that most uses of with can be captured with a single rule (Van Valin \& LaPolla 1997: 381, 382), given in (5). There is a more recent version (Van Valin 2005: 113-114) version of the rule in (5), but it covers fewer cases than the 1997-version. I will therefore only use the version in (5) in this chapter.

(5) Rule for assigning with in English

Given two arguments, $x$ and $y$, in a logical structure, with $x$ lower than or equal to $y$ on the Actor-Undergoer Hierarchy, and a specific grammatical status (macrorole, head of NP), assign with to the y-argument iff it is not selected for that status.

Essentially, this rule states that the non-selected y-argument of two candidates, $\mathrm{x}$ and $\mathrm{y}$, is marked by with. They can also capture the attribute reading of with, explored in chapter 7 . Attributive readings constitute a non-default realization of the RP and as such, the preposition with comes into play. In other words, with marks the default choice of two candidates for a specific status when the non-default choice is selected for it. As I will explore in the next section, this is how instrument marking is captured.

The status and the marking of causees are more complicated, as English causative constructions consist of multiple cores. Bolivian Quechua (see (7.15)), by contrast, has causative constructions that consist of a single core (nuclear-level juncture). As the examples in (7.15) showed, the causee can be marked by either the instrumental or the accusative. Thus for Bolivian Quechua, it would not suffice to draw up a single rule for causees as they do not only have accusative but also instrumental as a marking option. Furthermore, instruments and causees occupy the same position in the LS and are both core arguments in Bolivian Quechua, but are marked differently, meaning that a single rule does not suffice to account for their marking. A similar situation exists in Kannada 
(Dravidian) with dative and instrumental ${ }^{4}$ as marking options (Van Valin \& LaPolla 1997: 588).

Even in English not all uses of with are captured by the rule in (5). In chapter 7, a predicative use of with was discussed (be-with' $(\mathrm{z}, \mathrm{x})$ ). Furthermore, potential instruments, implements and comitatives are expressed by NOT use' $(\mathrm{x}, \mathrm{y})$ or NOT be-with' ( $\mathrm{x}, \mathrm{y})$, meaning that the preposition is linked to a specific LS-configuration. This is contrasted by RRG's treatment of with, which is tied in with the linking process (Van Valin \& LaPolla 1997: 380). In the following sections, I will explore the linking for the different notions with the rule in (5) as a starting point and go into the syntactic status of each.

\subsubsection{Instrument and implement marking}

Instruments are assigned on the basis of the with-rule in (5) and are linked to arguments in the core. In the LS in (6b), the instrument is outranked for actorhood as the instigator is to the left of it. Because actor selection is absolute, there is no direct way around this principle. ${ }^{5}$ The instrument is also outranked for undergoerhood, leaving it as the NMR. Per rule (5), it is marked by with. A constituent projection of (6), together with its linking is given in figure 54 .

(6) a. Jacob broke the window with the rock.

b. [do' (Jacob, Ø)] CAUSE [[do' (rock, Ø)] CAUSE [BECOME broken' (window)]]

4 In both Bolivian Quechua and Kannada, instrumental marking favors an agentive implicature on the causee, whereas the other marker disfavors the implicature (Van Valin \& LaPolla 1997: 588).

5 ISA is a strategy to assign actorhood to the instrument, by virtue of leaving the instigator position empty. This does not constitute a violation of actor assignment, however, as the highest overt argument is still assigned actorhood. 


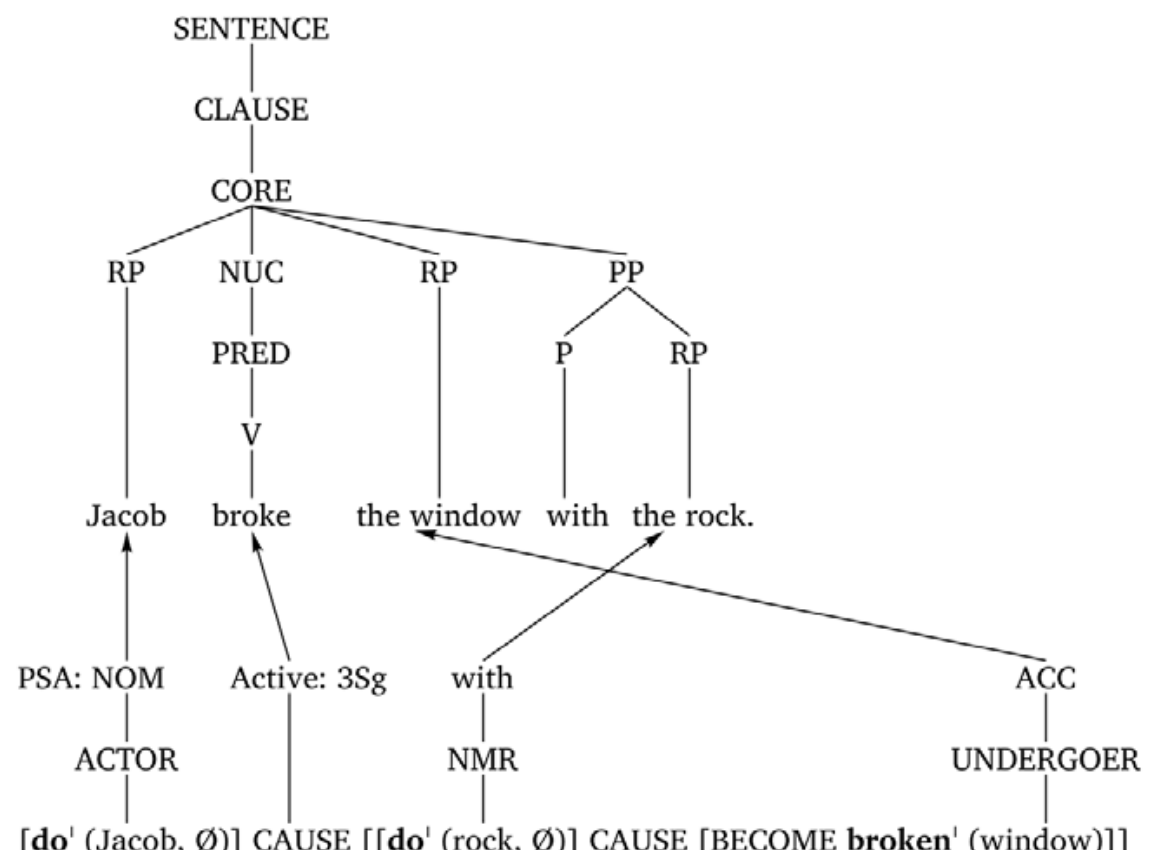

[do' (Jacob, Ø)] CAUSE [[do' (rock, Ø)] CAUSE [BECOME broken' (window)]]

Figure 54: Linking to syntax of a clause containing an instrument.

In terms of valence in the LS, an instrument-slot is dependent on the presence of a causal chain. Causal chains can be considered to have a lexically unfilled instrument-slot by default. The causal structure of causative verbs can be 'expanded' in order to provide more specific information. By its very nature, a causal chain can accommodate additional arguments that such an expansion adds. Syntactic valence is languagedependent.

I generally follow standard RRG as far as the rule in (5) is concerned in accounting for implements. Van Valin (2013) argues that the telic quale of the implement-referent is what licenses the use-predicate. The information in the telic quale for spoon specifies that it can be used to facilitate eating. This information licenses the use-predicate, introducing a new argument. Implement arguments are, as it were, optional. As it is licensed by a quale, it is appended to the base LS and falls under the scope of the rule in (5). Consider the examples in (7). 

a. Evie ate the soup with a spoon.
b. do' (Evie, [eat' (Evie, soup) $\wedge$ use' (Evie, spoon)]) \& INGR consumed' (soup)
c. Evie ate soup with a spoon.
d. do' (Evie, [eat' $($ Evie, soup) $\wedge$ use' $($ Evie, spoon)])

In (7a-7b), Evie is selected as actor and soup is selected as undergoer as it is the lowest-ranking argument. Spoon is outranked for actorhood because there is a 'better' candidate (Evie). Furthermore, spoon is a very unlikely candidate for actorhood, as it the y-argument of a predicate instead of the x-argument. In (7c), spoon is outranked for actorhood by the same logic. However, it could be argued that spoon is as good a candidate for undergoer as soup: Both are $\mathrm{y}$-arguments of a predicate under the scope of do', that is, both are of equal rank. The left-most argument (soup) is selected as undergoer, leaving spoon to be marked by with, in accordance with the rule in (5). Syntactically, the implement is realized as an argument in the core. Contrary to LSs with instruments, those with implements do not have an argument slot available for the 'tool'. The telic quale creates an extra slot. Qualia are the driver behind the creation of an extra slot and the process can be captured with a lexical rule (Van Valin 2013: 90):

$$
\begin{aligned}
& \text { do }^{\prime}\left(\mathrm{x},\left[\text { pred } ^ { \prime } ( \mathrm { x } , ( \mathrm { y } ) ) \ldots \rightarrow \text { do } ^ { \prime } \left(\mathrm{x},\left[\operatorname{prred}^{\prime}(\mathrm{x},(\mathrm{y})) \wedge \mathbf{u s e}^{\prime}(\mathrm{x},\right.\right.\right.\right. \\
& \mathrm{z})]) \ldots
\end{aligned}
$$

In other words, the implement-PP is not the argument of a preposition, but rather the argument of a lexically augmented LS. This is the reason why it can be under the scope of the rule in (5). If it were the argument of a predicative with, then marking would follow from the preposition itself. In case of the full LS of instruments, it is clear then, why the instrument does not occur twice. If with were predicative here, it would occur twice. Once as a result of the rule in (5) and once as the result of the predicative preposition. Because it is part of a (derived) LS, it is an argument and not an argument-adjunct, as that would presuppose a predicative with. 
Contrary to standard RRG, Jolly (1993: 298) proposes to treat the implement-with as a predicative preposition that has the semantic content of the use-predicate. This is problematic for several reasons. First, in chapter 7, I presented evidence in favor of a predicative with in the LS-form of be-with'. Recognizing use' as another predicative with would split the uses of with, ultimately leading to a treatment of all uses of with as separate entries. This is rejected by Van Valin \& LaPolla (1997: 377) as a non-analysis. Second, the rule in (5) is a unified, simple rule that works without exception. There is no reason, then, to assume that it does not correctly explain implement-with. Third, assuming two predicative withs with very different corresponding LSs (use' vs. be-with') is problematic from the point of view that predicative prepositions are more basic and historically precede non-predicative ones (Jolly 1993: 275-276). If this is so, then which predicative with is the basic, 'older' one and why do two predicative withs exist at the same time in language? How did one evolve from the other? Furthermore, why do their LSs take on such different forms? A representation of the linking to syntax of (7a) is given in figure 55. 


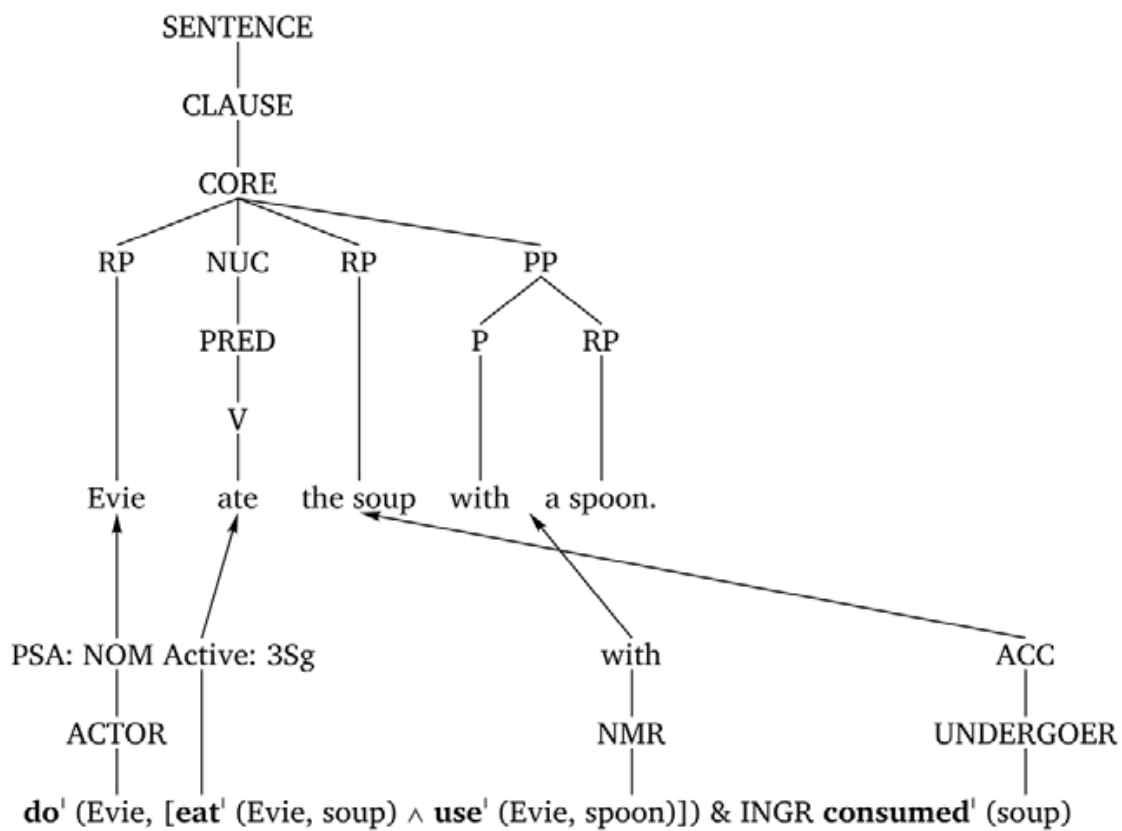

Figure 55: Linking to syntax of a clause containing an implement.

\subsubsection{Causee marking}

In chapter 7 , a phenomenon where causees take instruments was explored. This dissertation is concerned with instruments, implements and their marking in simple cores. Because English causee constructions involve more than simple cores, I will use French as a language of illustration. In French, causatives expressing more direct causation involve nuclear junctures (for an overview of the complete theory of juncturenexus relations in RRG, see Van Valin 2005, chapter 6), whereas weaker causation involves multiple cores. The coordination of cores means that both cores have their own set of arguments and one argument is shared. Consider the example from French in (9). In the example in (9), the argument fean is semantically shared by the verbs. Syntactically, it is part of the first core. 
(9) Je laisserai fean manger les gateaux

1SG let.FUT.1SG Jean eat.INF DEF cake.PL

'I will let Jean eat the cakes.' (Van Valin 2005: 189)

The example in (9) features permissive/enabling causation. More direct forms of causation are expressed (in French) as a combination of nuclei. An example of this is given in (10). The difference between the coordination of cores and the coordination of nuclei is visible (in French at least) in that with the former type the shared argument in (9) occurs in between the two verbs (cf. Van Valin 2005: 191). With nuclear cosubordination ((10a)), the two verbs occur directly next to each other. This situation also exists in Dutch and German ((10b-10c)). English, by contrast, expresses (10a) in terms of core coordination ((10d)).
a. Jean a fait courir Simon.
Jean AUX.3SG make.PTCP run Simon
'Jean made Simon run.' (French)
b. Jean heef-t Simon doe-n lop-en.
Jean AUX-3SG Simon do-INF run-INF
'Jean made Simon run.' (Dutch)
c. Jean hat Simon lauf-en lass-en.
Jean AUX.3SG Simon run-INF let-INF
'Jean made Simon run.' (German)
d. Jean made Simon run.

The syntactic difference between (9) and (10a) is given in figures 56 (adapted from Van Valin 2005: 189) and 57, respectively. 


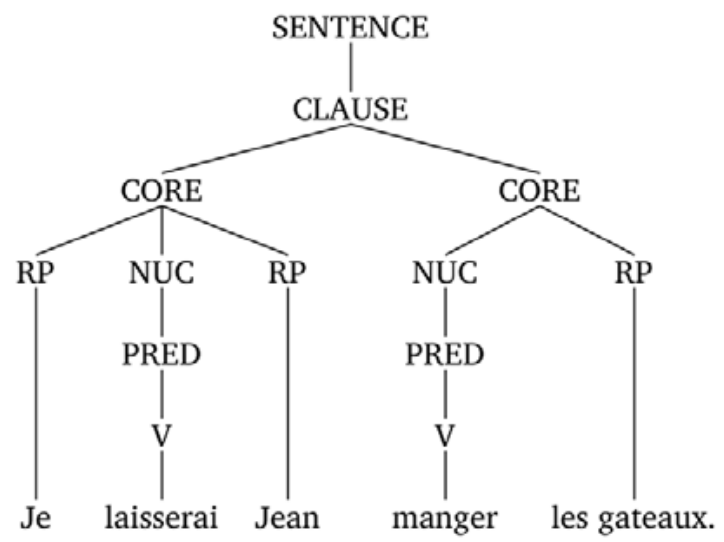

Figure 56: Syntactic structure of a French sentence expressing permissive causation.

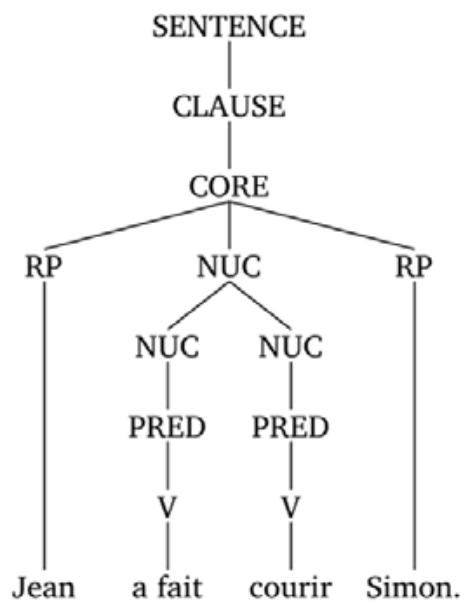

Figure 57: Syntactic structure of a French sentence expressing direct causation.

As far as linking is concerned, nuclear junctures behave the same way as simple, lexical verbs. In other words, the linking algorithm applies as it would with simple sentences. To ascertain the marking of causees taking 
instruments, I will explore several key examples, starting with the simplest structure.
a. Jean a fait manger Marie. Jean AUX.3SG make.PTCP eat Marie 'Jean made Marie eat.'
b. [do' (Jean, Ø)] CAUSE [do' (Marie, [eat' (Marie, Ø)])] $\mathrm{A}$
c. Jean a fait manger la soupe à Jean AUX.3SG make.PTCP eat DEF soup to Marie.
Marie
'Jean made Marie eat the soup.'
d. [[do' (Jean, Ø)] CAUSE [do' (Marie, [eat' (Marie,

The difference between $(11 a-11 b)$ and $(11 c-11 d)$ in terms of marking follows from general principles and their application in French. In (11a$11 b)$, Jean is the actor as it is the highest-ranking argument in the LS. Similarly, Marie is the undergoer as it is the lowest-ranking argument. French does not mark undergoers morphologically but positionally: It immediately follows the nucleus. In $(11 \mathrm{c}-11 \mathrm{~d})$, the same principle is at work. The undergoer in $(11 \mathrm{c}-11 \mathrm{~d})$ is soupe and is assigned the postnuclear position. Marie is NMR and is assigned the dative preposition $\grave{a}$ as it is the standard marker for NMRs, parallel to the rule governing English to. Parallel to the with-rule in English, there is the avec-rule marking instruments. In (12a-12b), this rule applies as couteau is a nonselected candidate for actorhood.
a. Marie a coupé le pain avec le couteau. Marie AUX.3SG cut.PTCP DEF bread with DEF knife 'Marie cut the bread with the knife.'
b. [do' (Marie, Ø)] CAUSE [[do' (couteau, Ø)] CAUSE [BECOME cut' (bread)]]


If causees take instruments, there are two NMRs. An example is given in $(13 a-13 b)$. The first NMR is the causee and the second one is the instrument. The standard rule assigning avec would be problematic. For instance, Marie is a potential actor herself and, as Marie is not selected as actor, avec should be assigned. Yet, assigning avec would result in ungrammaticality. Furthermore, would the avec-rule be applied twice? Therefore, a rule capable of handling two NMRs and their relative ordering has to be established. If the instigator of $(13 a-13 b)$ is left out, the result is the more basic structure in (13c). In (13c), Marie would be assigned actorhood and the instrument would be assigned avec. If the chain is expanded in such a way that an instigator is added, Marie loses its instigator status, leaving two intermediate effectors with both as potential actors. Marie is a better candidate for actorhood than couteau, as its referent ranks higher on the actionality scale. One could posit then, that the lower of the two arguments in terms of actionality is assigned avec and the higher is assigned $\dot{a}$. It would not be correct to assume that the higher position in the LS correlates with $\grave{a}$-marking and the lower LS-position correlates with avec-marking. In chapter 7, I explored a French example ((7.23a)) with two relevant interpretations. These interpretations are also available for (13a). The first is a typical causeeinterpretation (LS in (13b)): Jean makes Marie do something and that is cutting the bread, using a knife to do this. The second is an interpretation where Jean uses a knife to make Marie do something and that is cutting bread. Parallel to the LS I proposed in (7.24b), the second reading has the instrument occupying a higher LS-slot than the causee (LS in (13d)). This LS shows that the LS-positions alone cannot account for the marking. If they did, then the instrument would be marked by $a$ and the causee would be marked by avec. However, such marking is ungrammatical. It is therefore necessary - in case of two NMRs - to tie in the assignment rules with the referents' actionality status. Couteau ranks lower and is assigned avec and Marie ranks higher in terms of actionality and is assigned $\grave{a}$. The rule I propose for this is given in (13e). Following the Paninian principle (cf. Kiparsky 1993) that more specific rules take priority over more general ones, the more specific rule in (13e) takes 
precedence over the more general rules assigning avec and $\grave{a}$, respectively.
fait
couper le pain
a. Jean $a$
Jean AUX.3SG make.PTCP cut.INF DEF bread
à Marie avec un couteau.
to Marie with INDEF knife
b. $\quad\left[\mathbf{d o}^{\prime}(\mathrm{Jean}, \varnothing)\right]$ CAUSE $\left[\left[\mathbf{d o}^{\prime}(\right.\right.$ Marie,,$\left.)\right]$ CAUSE $\left[\left[\mathbf{d o} \mathbf{\prime}^{\prime}\right.\right.$ $\mathrm{NMR}_{1}$ (couteau, Ø)] CAUSE [BECOME cut' (pain)]]] $\mathrm{NMR}_{2}$
c. $\quad\left[\right.$ do' $^{\prime}($ Marie, $\left.\varnothing)\right]$ CAUSE $\left[\left[\right.\right.$ do' $^{\prime}$ (couteau, $\left.\left.\varnothing\right)\right]$ CAUSE [BECOME cut' (pain)]]
d. [do' (Jean, Ø)] CAUSE [[do' (couteau, Ø)] CAUSE [[do' (Marie, Ø)] CAUSE [BECOME cut' (pain)]]]
e. Rule for assigning avec and $a$ in LS with two NMRs Given a logical structure with two non-macrorole arguments, $\alpha$ and $\beta$, with both as potential actors in terms of the AUH, assign avec to NMR $\alpha$ if its referent's actionality is lower than NMR $\beta$ 's referent's actionality. Assign à to NMR $\beta$. 


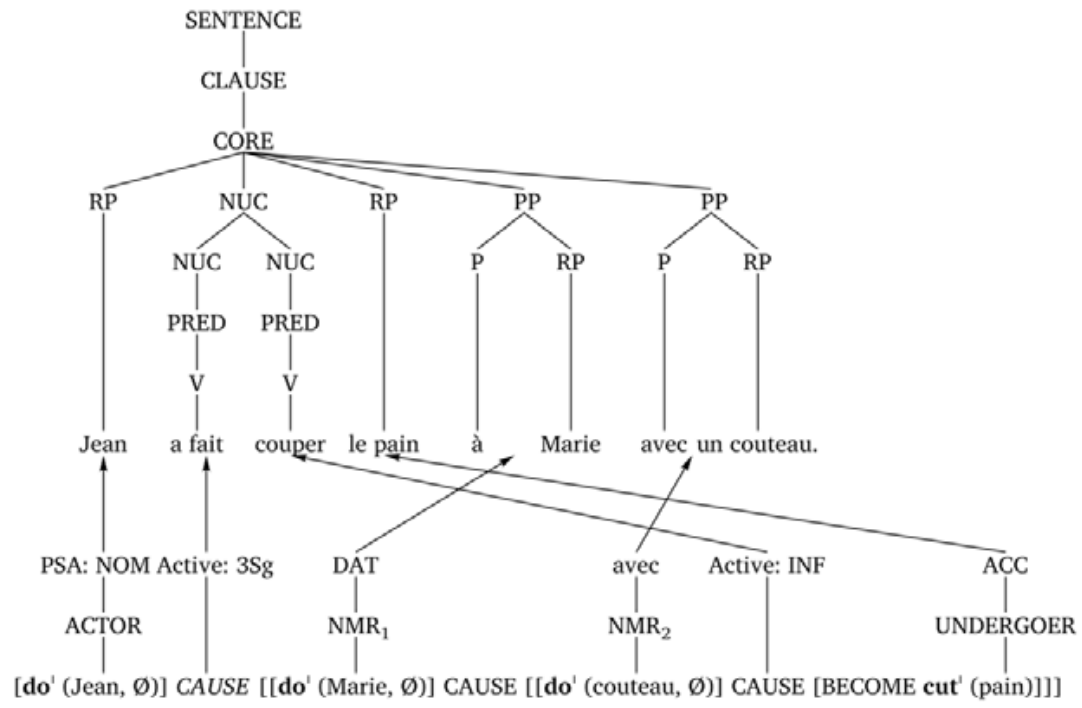

Figure 58: Causee under the scope of direct causation taking an instrument.

The example above is an example of direct causation. French has two causative auxiliaries (faire and laisser) whereas English has three (make, have, let). To express the difference between direct and indirect causation, for which English uses two different auxiliaries (make vs. have), French cannot use laissser because it expresses permissive and enabling causation. Rather than leaving the structure ambiguous like Dutch ${ }^{6}$ or German, French has a linking option where the second, embedded LSsegment also takes two macroroles (Van Valin 2005: 236). This creates a problem as the compound LS would have three macroroles: An undergoer (contributed by the embedded LS), an actor (contributed by the first section of the LS) and a second actor (contributed by the embedded LS). This would create three macroroles for one core, which is not allowed. Because of this restriction, the actor of the matrix-level LS is selected as

6 As I pointed out in chapter 5, Dutch has a disambiguation strategy but it is not open to all verbs. The French linking option is fairly productive, by contrast. Also recall that Netherlandic Dutch only has one causative auxiliary (laten). 
PSA and the second actor is realized in the periphery, marked as a passive agent so as not to violate the restriction. The main piece of evidence in favor of analyzing the second actor as being realized in the periphery is that it is optional. Contrary to the causee in (13a), it can be left out. The instrument-effector in (14) is an NMR, just as in (13a) and its marking is accounted for by the avec-rule. An example of this is given in $(14 a-14 b)$ and the linking is given in figure 59.

a. Jean a fait couper le pain par Jean AUX.3SG make.PTCP cut.INF DEF bread by Marie avec un couteau.

Marie with INDEF knife

'Jean had Marie cut the cake with a knife.'

b. $\quad\left[\mathbf{d o}^{\prime}(\mathrm{Jean}, \varnothing)\right]$ CAUSE $\left[\left[\mathbf{d o}^{\prime}(\right.\right.$ Marie,,$\left.)\right]$ CAUSE $\left[\left[\mathbf{d o} \mathbf{\prime}^{\prime}\right.\right.$ $A_{M}$ $\mathrm{A}_{2}$ (couteau, Ø)] CAUSE [BECOME cut' (pain)]]] $\mathrm{NMR}_{1}$

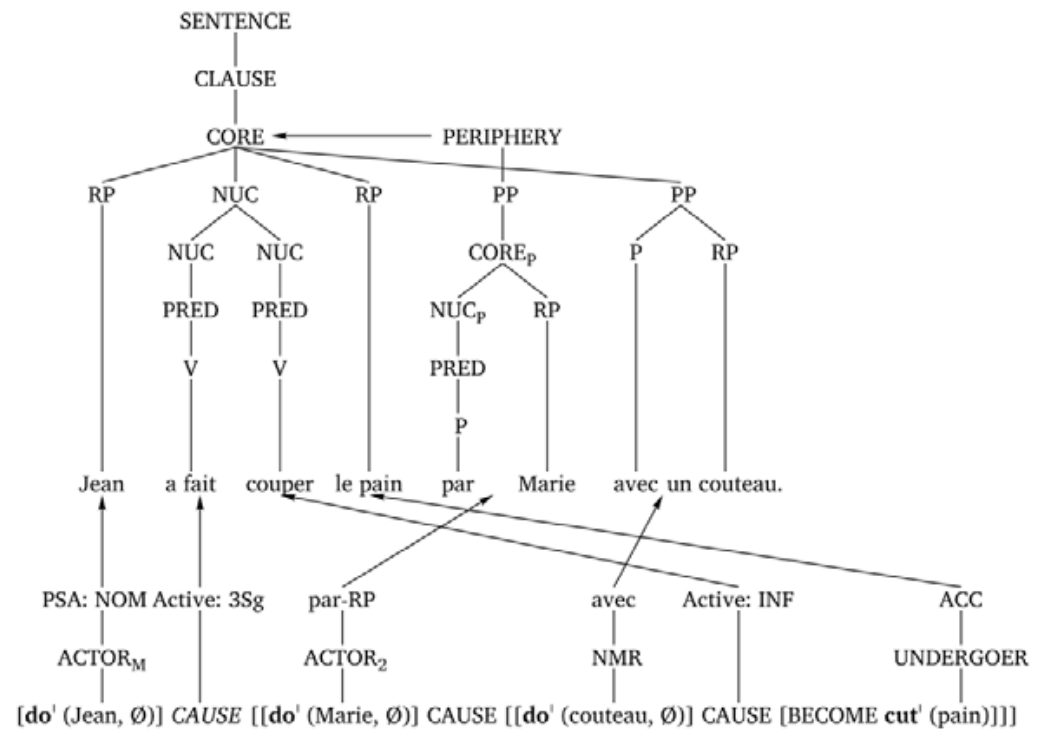

Figure 59: Causee under the scope of indirect causation taking an instrument. 
As far as causation is concerned, the main difference is the strength of causation (direct and indirect causation, respectively). The initial causal operator is italicized (CAUSE) to indicate its underspecified nature. As I pointed out in chapter 7 , the precise interpretation (CAUSE vs. IND) is supplied by Holisky's principle. In case of (13a), the $\grave{a}$-marker serves as information to the contrary and the causee is interpreted as being under the scope of direct causation. Par allows for a volitional reading of the causee and the type of causation is considered to be indirect. In other words, I do not wish to posit two different versions of faire in the lexicon, but rather an underspecified one. This ties in to the discussion of the different types of causation: Languages allow for a degree of vagueness when it comes to expressing the strength of causation. French is no different here. The construction in (13) unambiguously expresses direct causation. The default interpretation for (14) is one of indirect causation, yet it can be interpreted as expressing direct causation given the right context (Simon Petitjean, p.c.). In this thesis, I assume the default reading for the sake of clarity. Both constructions can be summarized in terms of a unified constructional schema. ${ }^{7}$ It is given in table 27.

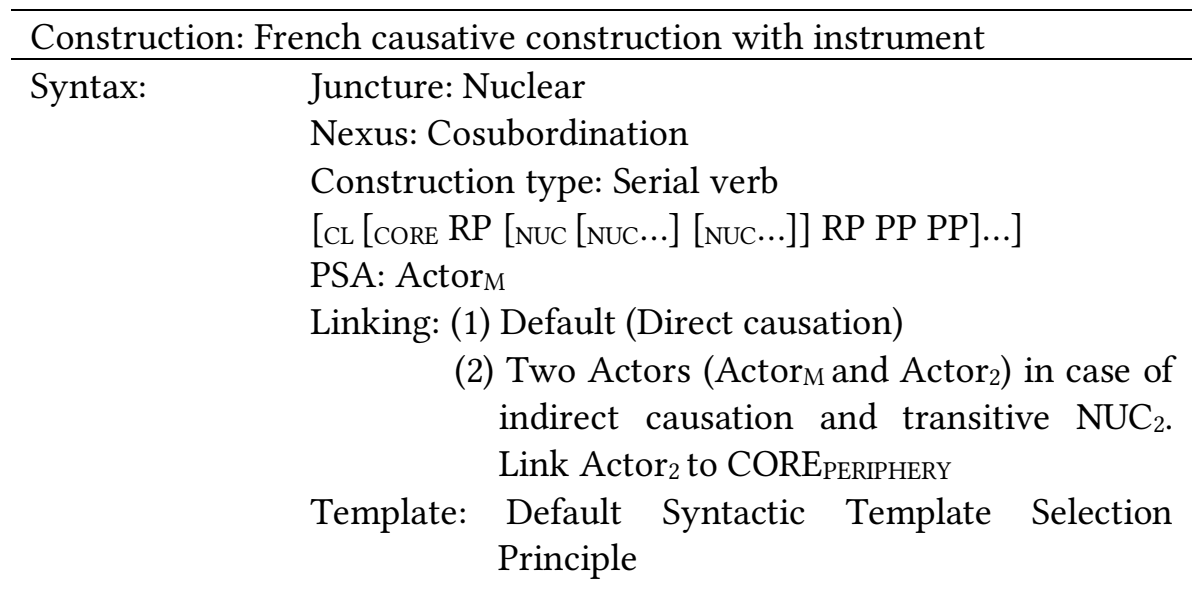

$7 \quad$ AM stands for actor on the matrix level. 
Morphology: Verb: $\mathrm{NUC}_{1}$ : Default finite

$\mathrm{NUC}_{2}$ : Non-finite

Argument marking: Default (linking (1))

Par (linking (2))

Semantics: $\quad$ [PRED $\left.{ }_{\mathrm{NUC}}\right]$ CAUSE [PRED $\left.\mathrm{NUC}_{2}\right]$

Pragmatics: IF: unspecified

Focus structure: unspecified

Table 27: Constructional schema for French causee construction with an instrument.

\subsubsection{Comitative marking}

As pointed out in chapter 7, comitatives are essentially conjoined arguments where only one is selected as actor or undergoer. The other is linked as an oblique core argument (in a with-PP). In terms of linking, comitative marking can be accounted for by the rule for NMRs in (5), as the object of with is still an argument of the main LS. This makes the comitative PP similar in status to an instrumental PP; both are nonpredicative PPs functioning as arguments in the core. Consider:

a. Todd and Michael destroyed the ship.

b. Todd destroyed the ship with Michael.

In (15a), the conjoined RP Todd and Michael is selected as actor and becomes the PSA. In (15b) only Todd is selected as actor and PSA while ship is the undergoer. This leaves Michael as an intermediate argument. To use Jolly's (1993) terms, Michael is a potential macrorole candidate but not selected for a specific macrorole, leaving it as an NMR. The rule for non-predicative with applies and Michael is realized in a PP. The constituent projection for (15b) is given in figure 60 . 


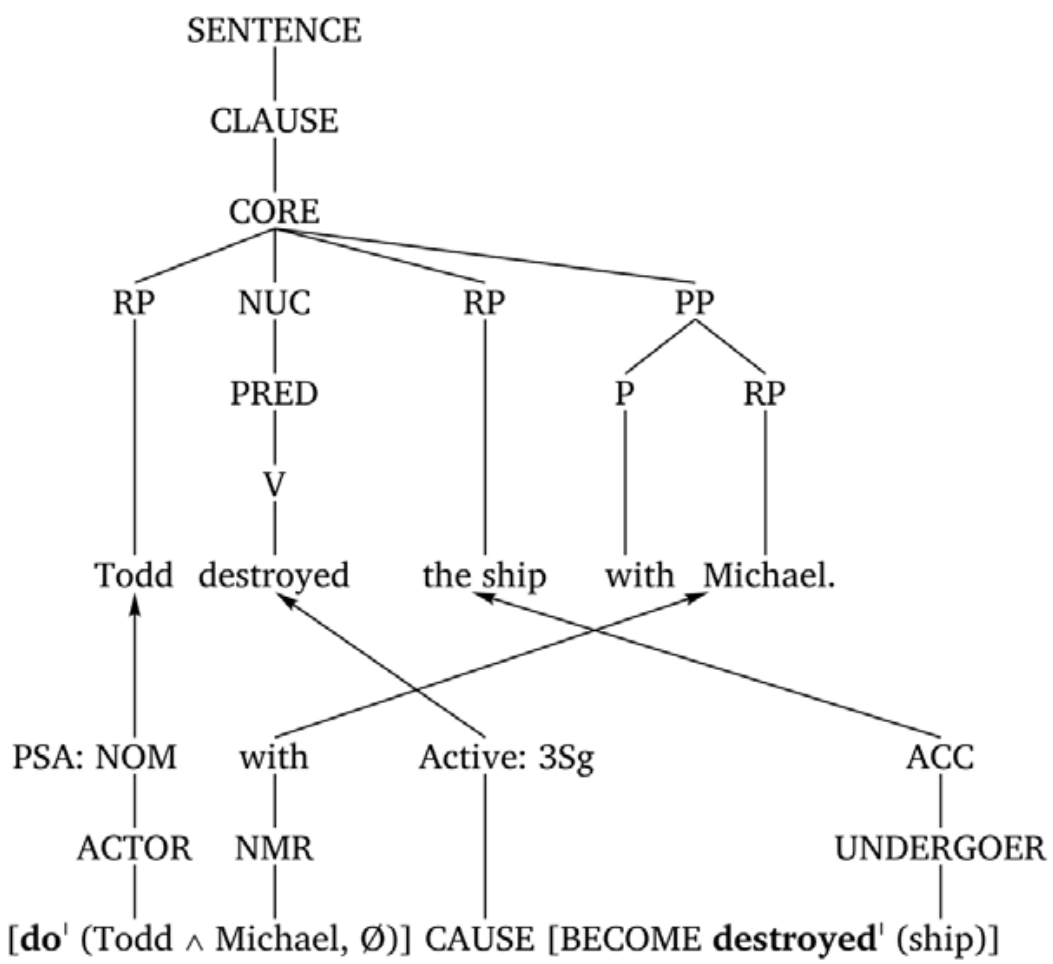

Figure 60: Linking to syntax for Todd destroyed the ship with Michael.

The NMR-marking rule is usually considered in the context of arguments that are not selected as actor, like instruments. Yet, it also applies to the lower section of the AUH. As undergoer selection is variable, the potential undergoer argument that is not selected as undergoer is (in English) canonically marked by with. In chapter 7, undergoer- and NMRcomitatives were discussed. Their marking is also accounted for by the rule in (5). In the example in (16b), only one argument is selected as undergoer, leaving the other as a non-macrorole argument. Because it is a potential candidate for a specific status (in this case undergoerhood) but not selected as such, it is marked by with. The other NMR, Sam is marked according to the default NMR-rule. The LS for $(16 a-16 b)$ is given in (16c). 
(16) a. Jack served [cheese and wine] to Sam.

$$
\text { A U NMR }
$$

b. Jack served cheese [with wine] [to Sam].
A
$\mathrm{U} \quad \mathrm{NMR}_{2} \quad \mathrm{NMR}_{1}$

c. $\quad\left[\right.$ do' $\left.^{\prime}(J o h n, \varnothing)\right]$ CAUSE [BECOME have' (Sam, cheese $\wedge$ wine)]

The marking of the NMR-comitative follows the same principles. The example from chapter 7 is repeated in (17). In (17a) the lowest-ranking argument is chosen as NMR and the intermediate argument is selected as undergoer. Similar to (16b), one of the arguments is not selected for a certain status (here: NMR) and is marked by with as a result $((17 b-17 c))$. In chapter 7, I called this phenomenon NMR-splitting, as one NMR is split into two NMRs and the most topical one is unmarked.
a. John served his guests [the entree and the soup]. A NMR
b. John served his guests the entree with the soup.
c. [do' (John, Ø)] CAUSE [BECOME have' (guests, A
entree $\wedge$ soup)]
$\mathrm{NMR}_{1} \quad \mathrm{NMR}_{2}$

There does seem to be a limitation to comitative phenomena. In the examples in (16) and (17) the verbs allowing variable undergoer selection are dative shift verbs. The main difference (in English) between dative shift verbs and the other class of verbs that allow variable undergoer selection (transfer-verbs) is that the former leave the shifted NMR unmarked (Van Valin 2005: 114), as is the case in (17a). Consider an example of a transfer-verb in (18). 
(18)

a. Nicholas presented the notebook and the pad

A

[to Everett].

NMR

b. Nicholas presented Everett [with the notebook and the

A

$\mathrm{U}$

NMR pad].

In (18a), the default MR-assignment rules apply. In (18b), the intermediate argument is assigned the undergoer macrorole and the lowestranking argument is assigned NMR-hood. It is possible to apply comitative linking to (18a) but not to (18b):

(19) a. Nicholas presented the notebook with the pad to Everett.

b. $\quad$ Nicholas presented Everett [with the notebook]

A

$\mathrm{U}$

NMR1

[with the pad].

NMR2

With comitative marking and marked undergoer selection the arguments in question are eligible for a certain status but not selected as such. In the inadmissible (19b), the with-rule applies twice, once for the marked undergoer selection and once to split the NMR in two NMRs. Both linking procedures can individually apply, as illustrated by (18b) and (19a), but not together. It seems that the marked undergoer-with takes priority over comitative with. This is not a linking problem in itself, as applying marked undergoer selection and comitative linking together is possible in dative shift verbs ((20)). Rather, there is a constraint that prohibits two withs with essentially the same function and gives marked undergoerwith priority.

$$
\begin{aligned}
& \text { fack served Sam [cheese] [with wine]. } \\
& \text { A } \quad \text { U }
\end{aligned}
$$




\subsubsection{Inanimate comitatives}

In chapter 7, a type of 'comitative' was explored where no coauthorhood exists:

(21) a. Edward ran to the hospital with the hammer.

b. Joan ran to the store with the goldfish.

It was argued that in such cases, the LS-sequence be-with' $(\mathrm{z}, \mathrm{x})$ is appended to the main LS. This constitutes the prime predicative use of with. The sequence be-with' $(\mathrm{z}, \mathrm{x})$ introduces a new argument that cannot be licensed by the base LS and it crucially shares an argument with that same base LS, making this use of with an argument-adjunct preposition. Consider the LSs for $(21 \mathrm{a}-21 \mathrm{~b})$ :

(22) a. [[do' (Edward, [run' (Edward)]) \& INGR be-at' (hospital, Edward)] $\wedge$ be-with' (hammer, Edward)]

b. [[do' (Joan, [run' (Joan)]) \& INGR be-at' (store, Joan)] $\wedge$ be-with' (goldfish, Joan)]

The sentences in (21) contain two argument-adjuncts: The with-PPs and the goal PPs. The constituent projection and the linking for (21a) is given in figure 61. 


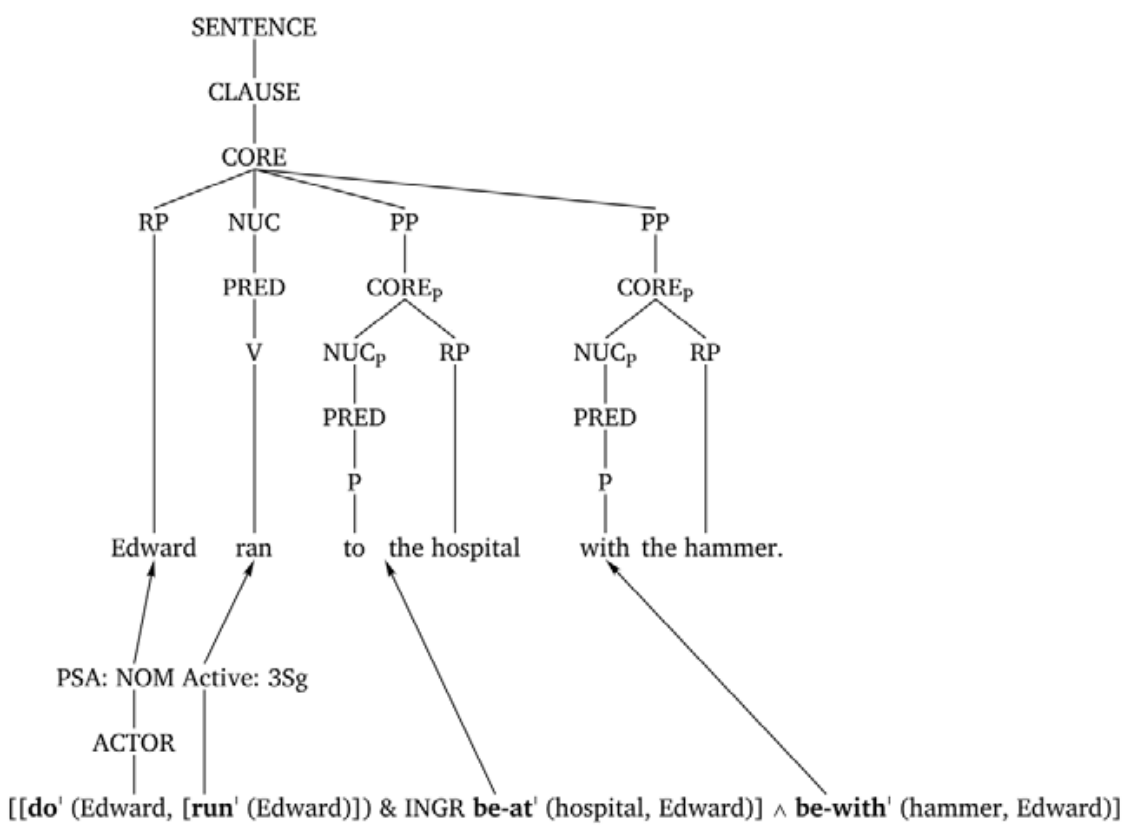

Figure 61: Linking to syntax for Edward ran to the hospital with the hammer.

\subsubsection{Marking of proper part-implements}

In chapter 7, it was pointed out that proper parts used as implements have a preference for a different marker. Consider the following examples with their LSs:

(23) a. The digger dug a hole by means of its scoop.

b. The computer virus crippled the mainframe by means of its coding.

c. The digger dug a hole with its scoop.

d. The computer virus crippled the mainframe with its coding.

e. $\quad\left[\left[\right.\right.$ do' $^{\prime}$ (digger, Ø)] CAUSE [BECOME dug' (hole) $] \wedge\left[\right.$ do' $^{\prime}$ (digger, [use' (digger, its scoop)])]] 


\section{f. [[do' (computer virus, Ø)] CAUSE [BECOME crippled' (mainframe) $] \wedge\left[\mathbf{d o}^{\prime}\right.$ (computer virus, [use' (computer virus, its coding)])]]}

The sentences in $(23 \mathrm{c}-23 \mathrm{~d})$ are grammatical but less acceptable than their counterparts in (23a-23b). This means that as far as (23c) and (23d) are concerned, the normal with-rule that covers standard implements applies. The implement is eligible for undergoerhood but is not selected as such, leaving it to be marked by with. However, how can the linking with by means of be accounted for? The key feature here is that the implements in question are a proper-part relation to the effector. This information can be captured in terms of qualia. In qualia theory, the relation between parts of an entity and the whole are handled in terms of the constitutive quale. I propose the following (partial) qualia-annotation for coding and computer virus:
a. Coding (a)
Constitutive: programming subcomponent' (b)
Formal: digital sequence' (a)
b. Computer virus (b)
Constitutive: superordinate' (a)
Formal: Digital algorithm' (b)
Telic: [do' (b, [...])] CAUSE [BECOME pred' (y)]

The crucial information here is located in in the constitutive quale and it can be integrated with a prepositional assignment rule.

(25) Assign by means of to non-MR argument $y$ in LS segment use' $^{\prime}\left(\mathrm{x}, \mathrm{y}_{\mathrm{C}}\right)$.

The subscript with the y-argument refers to the constitutive quale in the sense that the slot filler must be listed in the lexicon as a proper part of the slot filler of the $\mathrm{x}$-argument. The rule in (25) is a much more specific rule than the one in (5). Therefore, the Paninian principle regarding the order of rules applies here as well: The specific rule outranks the more general one. It is important to point out, however, that the rule in (25) applies primarily to inanimates and their proper parts. This is evidenced 
by examples (7.58a-b), repeated here in (26). In (26a-26b), the rule in (25) does not apply. Applying (25) to animates and their proper parts produces very odd, and to most informants, ungrammatical results $((26 \mathrm{c}-26 \mathrm{~d})$ and (7.61i-7.61j)). The preference surrounding by means of is very similar in Dutch ((26e-26f)).

(26) a. He untied the knot with his teeth. (Nilsen 1973: 130)

b. I bit him with my false teeth. (Lyons 1968: 422)

c. $\quad$ *He untied the knot by means of his teeth.

d. "I bit him by means of my false teeth.

e. Het computer virus leg-de de computer DEF computer virus cripple-PST.3SG DEF computer lam met zijn code. VPR with POSS.3SG code

f. Het computervirus leg-de de computer DEF computer virus cripple-PST.3SG DEF computer lam met door middel van code. VPR with through means of code

\subsubsection{Marking of potential instruments, implements and comitatives}

It is possible to use Van Valin's (2013) approach of co-composition to account for potential instruments and implements. In chapter 7, I argued that potential instruments and implements can be accounted for by including NOT in the typical implement LS. The preposition without is very specific and is restricted to three cases: NOT have', NOT be-with' and NOT use'. NOT be-with' constitutes the predicative version of without and will be discussed below. As such, it does not need to be included the rule assigning the other cases of without. ${ }^{8}$ I propose to treat the assignment of non-predicative without in terms of the rule in (27a). Matching examples are given in (27b-27e).

8 I am aware that there are other uses of without, such as without enthusiasm. These uses fall outside the scope of this dissertation and will therefore not be explored here. 


\section{a. Rule assigning without in English}

Assign without to non-macrorole $y$-argument in the logical structure segment:...NOT pred' $(\mathrm{x}, \mathrm{y})$

b. Evie ate the soup without a spoon.

c. do' (Evie, [eat' (Evie, soup) $\wedge$ NOT use' (Evie, spoon)]) $\&$ INGR consumed' (soup)

d. The woman without the book

e. NOT have' (woman, book)

The assignment of without is predicted by the rule in (27a): Evie and soup are selected as actor and undergoer, respectively leaving spoon as NMR. As the correct LS-segment is present, the NMR is marked by without. There is a close resemblance to the rule governing from in English (Van Valin \& LaPolla 1997: 377). The crucial difference, however, is that the rule governing from includes either the BECOME or the INGR operator in the relevant LS-segment. In other words, despite the similarity, it and the rule in (27a) are quite distinct. The example in (27b) has a potential implement, but (27a) also captures potential instruments. Consider the example in (28a) below.

(28) a. Jacob broke the window without a rock.

b. [do' (Jacob, Ø)] CAUSE [BECOME broken' (window)] $\wedge$ [do' (Jacob, [NOT use' (Jacob, rock)])]

Here, too, a similar linking presents itself: facob is the actor and window is the undergoer. Rock is outranked for both and becomes the NMR. As the segment NOT pred' $(x, y)$ is present, both conditions of the rule are met and the argument is marked by without. Potential instruments have to be represented as in (28b), as any other configuration (e.g. negating the instrument in the causal chain) yields paradoxical results for the larger LS (see the examples in (7.67)). Essentially, I treat potential implements and instruments as the potential version of implements rather than of instruments. This has the consequence that the question of the source of the argument is raised once more. Van Valin (2013) assumes that implements are licensed by the telic quale of the referent. I propose to treat potential implements/instruments in virtually the same way. By 
explicitly stating that one is not using a certain tool, the assumption is that it is usually used in the state of affairs. This is illustrated by the lower acceptability of the second in each of the sentence pairs:
a. Abdul ate the soup without a spoon.
b. ?Abdul ate the soup without a telescope.
c. Evie watched the birds without binoculars.
d. ?Evie watched the birds without a hammer.

Telescopes and hammers are not readily used in eating or watching events and as a consequence, the examples in (29b) and (29d) sound odd. The telic quales of spoon and binoculars contain the information that they are used for eating and observing, respectively. Consider a partial qualia-entry for spoon and binoculars:

a. $\quad$ spoon (a)

Telic: do' $\left(b,\left[\mathbf{e a t}^{\prime}(\mathrm{b}, \mathrm{c}) \wedge\right.\right.$ use $\left.\left.^{\prime}(\mathrm{b}, \mathrm{a})\right]\right) \ldots$

Agentive: artifact' (a)

b. binoculars (a)

Telic: do' (b, [watch' $(b, c) \wedge$ use $\left.\left.^{\prime}(b, a)\right]\right) \ldots$

Agentive: artifact' (a)

This information creates the argument slot in the base LS, as explored in Van Valin (2013). Contextually supplied information then provides the NOT part of the LS-segment. Then, the rule in (27a) applies. ${ }^{9}$ This can be captured with a lexical rule for negated instruments and implements:

$$
\begin{aligned}
& \text { do }^{\prime}\left(\mathrm{x},\left[\text { pred } ^ { \prime } ( \mathrm { x } , ( \mathrm { y } ) ) \ldots \rightarrow \text { do } ^ { \prime } \left(\mathrm{x},\left[\text { pred }^{\prime}(\mathrm{x},(\mathrm{y})) \wedge \mathrm{NOT} \text { use }^{\prime}\right.\right.\right.\right. \\
& (\mathrm{x}, \mathrm{z})]) \ldots
\end{aligned}
$$

The constituent projection for (27b) is given in figure 62 .

9 It might be confusing that English with has some superficial similarity to without. However, in languages like Dutch (met vs. zonder), German (mit vs. ohne), French (avec vs. sans) and Bulgarian ( $s$ vs. bez) they are quite distinct. 


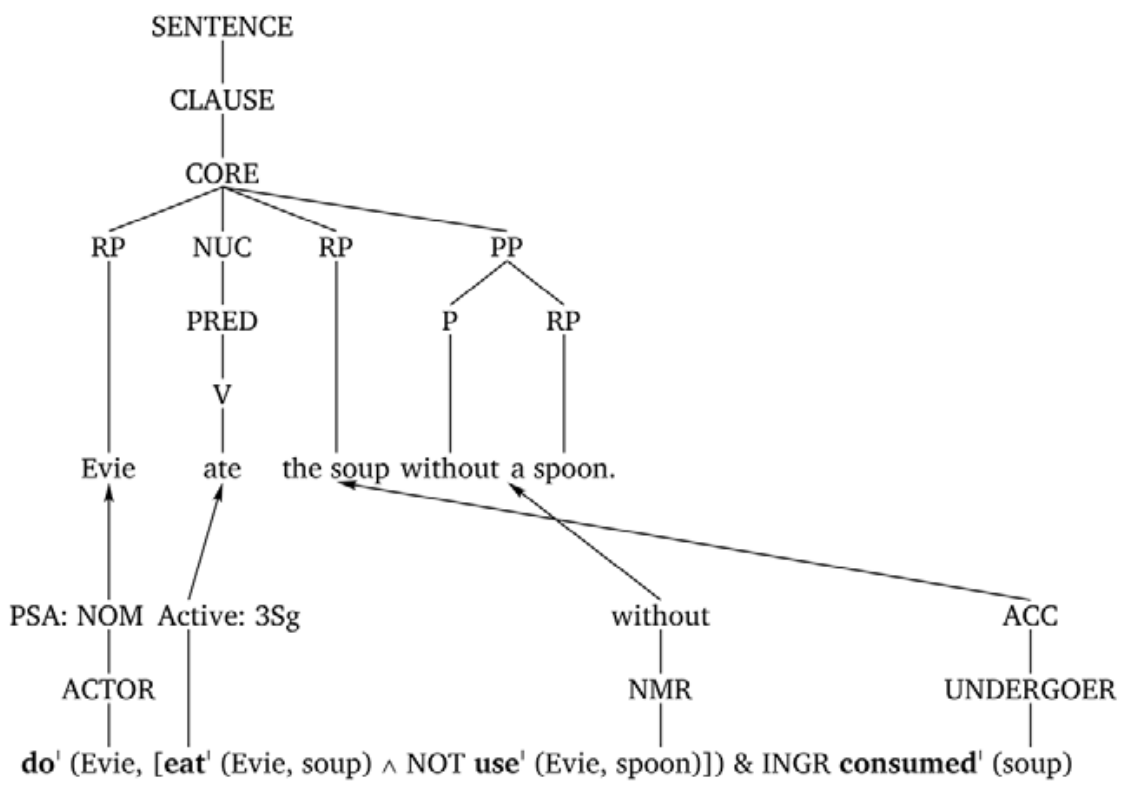

Figure 62: Linking to syntax for Evie ate the soup without a spoon.

As is the case with many prepositions, there is also a predicative version of without. This use was introduced in section 7.4 as the potential version of comitatives. It might seem counterintuitive to treat potential comitatives as involving a predicative preposition when normal comitatives are the result of argument marking options. Yet, as I explored in section 7.4, treating potential comitatives as a kind of linking option is implausible. Parallel to predicative with (be-with'), I propose NOT bewith'. I assume that predicative without is, similar to predicative with, a class 2-preposition (cf. Jolly 1993). That is to say, it introduces a new argument and shares an argument with the main LS. Consider:

(32) a. Caroline ran to the store without Elena.

b. [[do' (Caroline, [run' (Caroline)]) \& INGR be-at' (store, Caroline) $] \wedge$ NOT be-with' (Elena, Caroline)]

In (32a), without is predicative, meaning that the preposition takes an argument, rather being the result of argument marking rules. This 
approach can also account for a variation to (17), as given in (33d). The PP with the soup in (17) is essentially the result of a linking option. As I have illustrated before, marking an argument negatively in the LS produces implausible results. As I argue for a difference in status, some behavioral difference must present itself. The examples in (33) show that the non-predicative with-PP and the non-predicative without-PP are positionally constrained: There is a clear preference for them to occur in direct adjacency to the RP the soup and after the undergoer-argument, respectively. The predicative without-PP does not show this tendency; it is positionally less constrained. This is illustrated in (33a-33b) and (33c33d), respectively.

(33) a. John served the entree with the soup to his guests.

b. ?fohn served the entree to his guests with the soup.

c. John served the entree without the soup to his guests.

d. John served the entree to his guests without the soup.

As the predicative use of without introduces an argument to the LS and another is shared with that LS, syntactically, these PPs are argumentadjuncts. The linking for (32) is given in figure 63. 


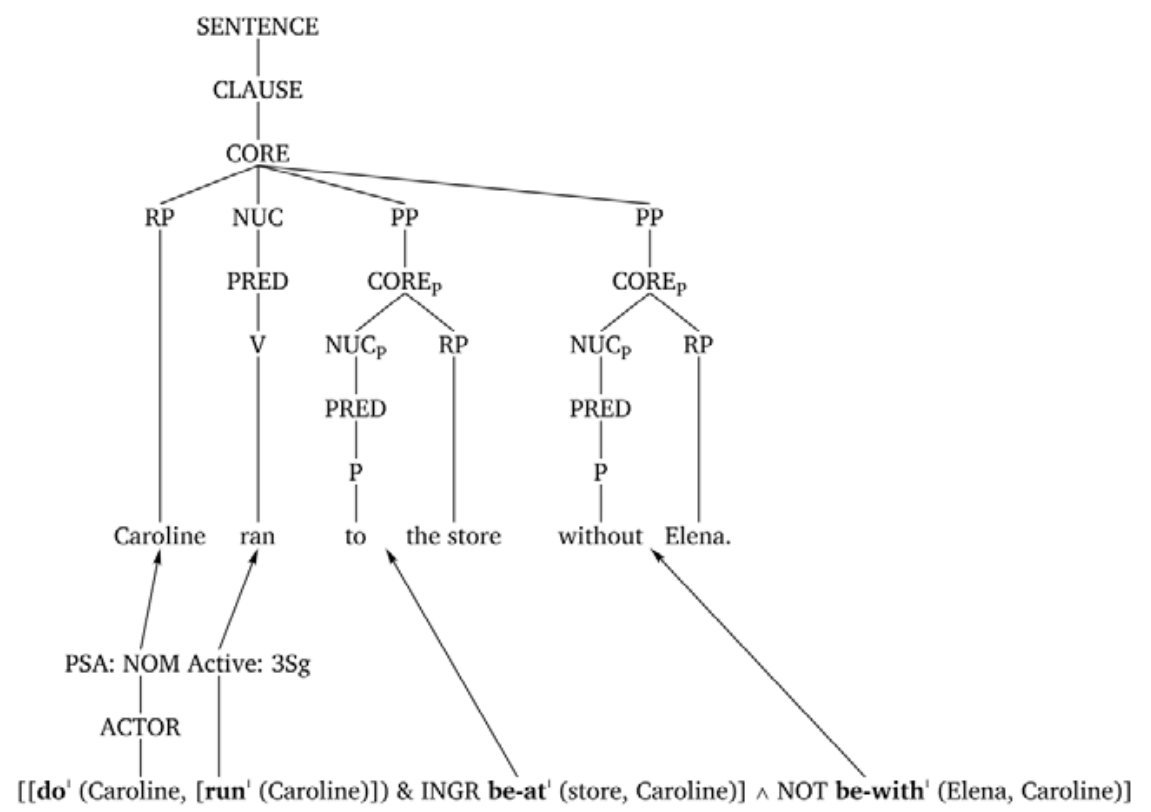

Figure 63: Linking to syntax for Caroline ran to the store without Elena.

\subsubsection{Extending predicative with and without}

Following Jolly, I assume that predicative uses of prepositions are more basic than non-predicative uses. Heine et al. (1991: 159) observed that there is a cross-linguistic pattern of grammaticalization where (for instance), the location case function serves a starting point with the expression of companion and instrument being often derived from it. Heine treats instrument as being more grammaticalized than companion but the essential insight is that both 'case functions' are derivative of the more basic location case function. What does this imply for my treatment of with?

In the previous sections, I argued in favor of recognizing a predicative with alongside its already recognized non-predicative version. Jolly's claim that the former function precedes the latter and are thus historically more basic, fits Heine's grammaticalization scale. The increasing grammaticalization in markers found by Heine has a direct reflection in 
the semantics (in terms of LS). These two claims can be combined with my treatment of with. This is schematized as in (34) below. The direction of the arrow indicates increasing grammaticalization, whereas the dashed line indicates the shift in corresponding LS-configuration.

Spatio-temporal
co-occurrence

be-with' $(z, x)$

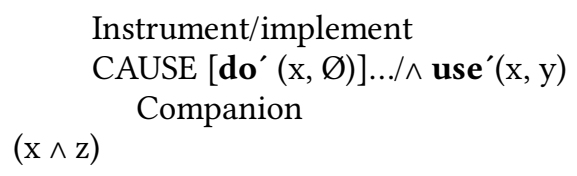

Non-predicative with

As far as without is concerned, I equally assume that the predicative use of without is more basic and that it can be modelled according to the same logic. This is given in (35).

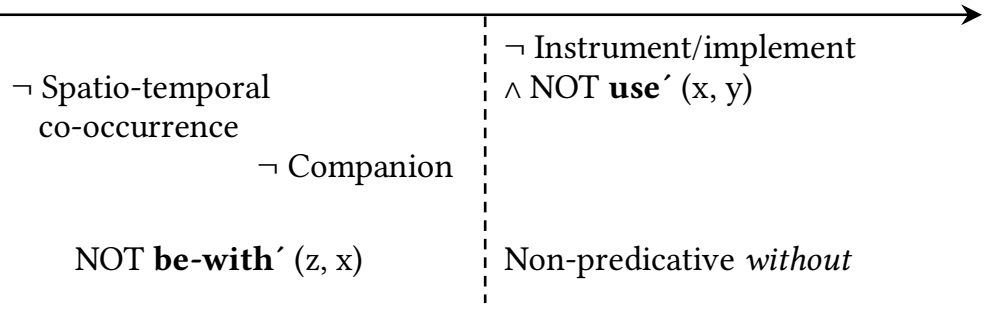

The driver of these grammaticalization clines can be argued to be roughly of the same type of metaphoric extension I referred to earlier (cf. Luraghi 2014, Lakoff \& Johnson 1980a \& b, Stolz 1996): Being together with someone in the same location (more precisely: spatio-temporal cooccurrence) is considered as a prototypical prerequisite to doing something together. Prototypical instrumentality can be seen a wielder and a tool being together in the same location and doing something together (in a more general sense). This line of reasoning can be traced to Lakoff \& Johnson's work on metaphors and more particularly on the metaphor where instruments are essentially treated as companions (Lakoff \& Johnson 1980b: 135ff.). In the European languages, the historical shift from comitative to instrument is commonplace and well-documented (Narrog 2014: 76) and the extension from location to comitative is also a wellestablished fact (Ibid.: 74). Stolz (1996) provides evidence in favor of languages extending instrumental morphology to include comitative 
functions rather than the other way around. This presents many problems for the claimed universality of Lakoff \& Johnson's instrument-ascompanion metaphor. Yet, Heine (1991), amongst others, has found evidence in favor of grammaticalization clines from many different source domains extending to instrumentality. Be that as it may, the extension from companionship to instrumentality is well established for the IndoEuropean languages and especially for the SAE-languages (Stolz 1996: 120) which are the core of this dissertation.

\subsection{Passive construction with an instrument}

Instrument constructions can also be passivized. Consider the examples in (36).

(36) a. Jack cut down the tree with the axe.

b. The tree was cut down by fack with the axe.

c. The tree was cut down with the axe.

The passive construction in (36b) is fairly straightforward from an RRG point of view. Passivization is treated in terms of PSA-modulation and argument modulation (Van Valin 2005: 116). That is to say, the PSA assignment is marked in that the lowest-ranking argument rather than the highest-ranking one is selected (in accusative systems). Argument modulation concerns the non-canonical realization of a macrorole argument. For English, this includes omitting it ((36c)), or realizing it in a by-PP as in (36b). In both (36b) and (36c), the actor ( Fack) is modulated. Semantically, however, fack, is still the instigator in the LS, meaning that the instrument does not change semantically or syntactically. Essentially, the same constructional schema can be posited as for ordinary passives, proposed by Van Valin (2005: 132). No reference is made to the instrument, resulting in the standard application of the linking algorithm. In other words, the occurrence of the instrument follows from general principles and does not need to be specified in any way. The schema for a plain English passive (in an adapted form) is given in table 28 . 
Construction: English passive construction

Syntax: template: -1 core slots

PSA: Undergoer arg. in terms of AUH

Linking: (1) PSA modulation (voice)

(2) Arg. modulation: Actor arg. omitted or in peripheral $b y$-PP

Morphology: Verb: Past participle

AUX: be

Semantics: $\quad$ PSA is not instigator of state of affairs but affected by it

Pragmatics: IF: unspecified

Focus structure: no restrictions; PSA = topic (default)

Table 28: English passive construction.

Sentences including implements can also be passivized:

a. Abdul ate soup with a spoon.

b. Soup was eaten by Abdul with a spoon.

c. do' (Abdul, [eat' (Abdul, soup) $\wedge$ use' (Abdul, spoon)])

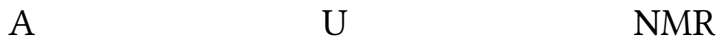

Similar to instruments, the implement is not affected by any element in the constructional schema. As both instruments and implements are unaffected by passivization, the plain constructional schema suffices. Even though it bears a slightly different name, the schema in table 28 is the basic one for English. In Dutch, passivizing the sentence with an instrument is only really acceptable if the passive agent is not omitted $((38 b))$. This information can be stored in a schema, detailing that the passive agent must (or should) be present. The sentences in (38) are the Dutch versions of those in (36).

$\begin{array}{lllll}\text { a. Jan vel-de } & \text { de boom met } \\ \text { Jan cut down-PST.3SG DEF tree with } \\ \text { een bijl. }\end{array}$


b. De boom werd ge-vel-d

DEF tree AUX\PST.3SG PTCP-cut down-PTCP

door fan met een bijl.

through Jan with INDEF axe

c. */?De boom werd ge-vel-d

DEF tree AUX\PST.3SG PTCP-cut down-PTCP

met een bijl.

with INDEF axe

\subsection{Passive ISA construction}

In chapter 6, an approach to ISA as a construction was explored. Following general construction grammar practice, I assume that constructions can be combined into more complex constructions that compound the characteristics of their components. A typical ISA example from chapter 6 has been repeated in (39).

(39) a. Jack cut the bread with the knife.

b. [do' (Jack, Ø)] CAUSE [[do' (knife, Ø)] CAUSE $\mathrm{A}+\mathrm{PSA}$ NMR

[BECOME cut' (bread)]]

$\mathrm{U}$

c. The knife cut the bread.

d. [do' $(\varnothing, \varnothing)]$ CAUSE [[do' (knife, Ø)] CAUSE [BECOME cut' $^{\prime}$ (bread)]] A+PSA

$\mathrm{U}$

The passivized version of ISA is just that: It is essentially an ISAconstruction (see table 22) combined with the passive construction as it was given in table 28. Rather than selecting the actor-argument, the undergoer is selected as the PSA. This is given in (40).

(40) a. The bread was cut by the knife.

b. [do' $(\varnothing, \varnothing)]$ CAUSE $\left[\left[\mathbf{d o}^{\prime}(\mathrm{knife}, \varnothing)\right]\right.$ CAUSE [BECOME cut' (bread)]]

$\mathrm{U}+\mathrm{PSA}$ 
My informants are divided with respect to the acceptability of the passive ISA construction. Only slightly more than half the native speakers accept it. Assuming that the construction is possible, its constructional schema is given in table 29.

\begin{tabular}{lc}
\hline Construction: English passive instrument as actor construction \\
\hline Syntax: & template: -1 core slots \\
PSA: Undergoer arg. in terms of AUH \\
Linking: (1) PSA modulation (voice) \\
(2) Arg. modulation: Actor arg. omitted or in \\
peripheral by-PP
\end{tabular}

Morphology: PSA: no explicit morphology

Verb: Past participle

AUX: be

Semantics: (1) x-argument of initial do' is unspecified

(2) Actor-macrorole is assigned to highest specified xargument of do'

(3) highest specified x-argument of do' must have minimum actional status as defined by the argument position

(4) PSA is not instigator of state of affairs but affected by it

Pragmatics: (1) Undergoer is topic, instrument-effector is backgrounded

(2) Natural Event Condition must be met

Table 29: English passive instrument as actor construction.

\subsection{Instrument unaccusative construction}

Webb (2008: 71ff.) explores an instrument-like construction which he calls the instrument unaccusative construction, which has hardly been discussed in the literature at all. An example is given in (41a). It is necessary to point out that, by a large margin, more than half of the native speakers I consulted unambiguously reject this construction. This could 
account for the sporadic attention in the literature for it. Furthermore, it does not fit naturally with the theory of instruments in general and with RRG. Nevertheless, as the construction is discussed in the literature and considered grammatical by a not insignificant number of people, I will follow Webb's own native speaker judgments and provide an RRG-based account. As the name implies, it is essentially an unaccusative construction with an instrument. Consider:

(41) a. The door opened with the key. (Webb 2008: 71)

b. The door opened.

c. BECOME open' (door)

d. Fohn opened the door with the key.

e. Fohn acted on the key, causing it to open the door.

f. [do' (John, Ø)] CAUSE [[do' (key, Ø)] CAUSE [BECOME open' (door)]]

I assume that the more basic (41b) is an intransitive accomplishment as it passes the relevant aktionsart-tests. The corresponding LS is given in (41c). In the sentence in (41d), key is clearly an instrument as it passes the relevant paraphrase ((41e)). The corresponding LS is given in (41f). The occurrence of an instrument in (41a) is somewhat confusing when contrasting it to (41e) and (41f). As RRG does not posit deletions or similar devices, the LSs and the linkings in (42) are inadmissible for (41a).

(42) a. $\quad\left[\mathbf{d o}^{\prime}(\varnothing, \varnothing)\right]$ CAUSE $\left[\left[\mathbf{d o}^{\prime}(\mathrm{key}, \varnothing)\right]\right.$ CAUSE [BECOME open' (door)]] A+PSA

$\mathrm{U}$

b. [do' (John, Ø)] CAUSE [[do' (key, Ø)] CAUSE

A NMR

[BECOME open' (door)]]

$\mathrm{U}+\mathrm{PSA}$

c. $\quad\left[\mathbf{d o}^{\prime}(\varnothing, \varnothing)\right]$ CAUSE $\left[\left[\mathbf{d o}^{\prime}(\mathrm{key}, \varnothing)\right]\right.$ CAUSE [BECOME open' (door)]] A $\mathrm{U}+\mathrm{PSA}$

d. The key opened the door.

e. The door was opened with the key by fohn.

f. The door was opened by the key. 


\section{g. $\quad{ }^{*}\left[\mathbf{d o}^{\prime}(\varnothing, \varnothing)\right]$ CAUSE $\left[\left[\mathbf{d o}^{\prime}(\mathrm{key}, \varnothing)\right]\right.$ CAUSE [BECOME open' (door)]] NMR \\ A}

The LS in (42a) links to the ISA-sentence in (42d), (42b) links to the passive instrument construction in (42e) and the LS in (42c) links to the passive version of ISA in (42f). The LS in (42g) is incorrect because it violates the AUH. A reasonable solution for (41a) is to posit the base LS in (41c), but with key included. The only plausible way to do this is to include an implement, as the causal paraphrase cannot even be applied due to verb's intransitivity. Consider the LS for (41a) in (43a) and a second example and its LS ((43b-43c)).
a. BECOME open' $($ door $) \wedge$ do' $^{\prime}\left(\varnothing,\left[\right.\right.$ use' $^{\prime}(\varnothing$, key $\left.\left.)\right]\right)$
b. The window broke with a hammer. (Chomsky 1972: 170)
c. BECOME broken' (window) $\wedge$ do' $\left(\varnothing,\left[\right.\right.$ use $^{\prime}(\varnothing$, hammer)])

The implement-section of the LS has to include an activity-component as implements can only be added to activity predicates. The x-argument of do' $^{\prime}$ and use' is unspecified. The marking of the implement is captured by the rule in (5): In (43c), hammer cannot be assigned actorhood. From the point of view of the whole LS, that would violate the AUH as the 'actor' ranks lower than the undergoer. If one were to argue that the second do' is sufficient to produce a 'new' actor, then the linking would assign it the PSA and link it to a plain transitive sentence with a causal chain. I assume, following the practice of the previous sections that MRassignment concerns the whole chain including the use-predicate. In this case, the intransitive nature of $(43 \mathrm{~b})$ prohibits an actor, leaving the $\mathrm{x}$ argument of do' unspecified. There are two potential candidates for undergoerhood (window and hammer). As window is selected, hammer is marked by with as the rule in (5) would predict. At this point, I wish to reiterate that many native speakers of English do not accept this construction. In Dutch $((44 a-44 b))$ and German $((44 c-44 d))$, this construction is utterly ungrammatical. 

a. ${ }^{*}$ De deur open-de zich met de sleutel. DEF key open-PST.3SG REFL with DEF key 'The door opened with the key.'
b. "Het raam brak met de hamer. DEF window break\PST.3SG with DEF hammer 'The window broke with the hammer.'
c. ${ }^{*}$ Die Tür öffne-te (sich) mit dem DEF door open-PST.3SG (REFL) with DEF Schlüssel.
key
'The door opened with the key.'
d. 'Das Fenster zerbrach mit dem Hammer.
DEF window break\PST.3SG with DEF hammer. 'The window broke with the hammer.'

\subsection{Middle construction with an instrument}

In chapter 6 , the difference between ability-readings and middle constructions was addressed. The middle construction I explored did not feature an instrument, yet it is sometimes possible to include one. I have given a more basic middle construction in (45a) with its LS in (45b). Due to RRG's inherent flexibility, including an instrument is unproblematic as the example in (45c) and its LS in (45d) illustrate.

(45) a. This glass breaks easily.
b. $\quad$ be' $^{\prime}\left(\left[\mathbf{d o}^{\prime}(\varnothing, \varnothing)\right]\right.$ CAUSE [BECOME broken' (glass)]], [easy'])
c. This glass breaks easily with a hammer. (Schäfer 2008: 2)
d. $\quad$ be' $^{\prime}\left(\left[\left[\mathbf{d o}^{\prime}(\varnothing, \varnothing)\right]\right.\right.$ CAUSE $\left[\left[\mathbf{d o}^{\prime}\right.\right.$ (hammer, $\left.\left.\varnothing\right)\right]$ CAUSE [BECOME broken' (glass)]]], [easy'])

The x-argument of be' has been expanded into a full causal chain, albeit with an unspecified instigator. Why do I posit a causal chain here but not in the LS for (41a)? There are two reasons for this: First, the 
'unaccusative' construction does not imply an instigator, whereas the middle construction, by its very nature, does (Stalmaszczyk 1993: 135). This is also evidenced by Van Valin \& LaPolla's (1997: 417) proposal to include an unspecified $\mathrm{x}$-argument of the initial do'. Second, the aktionsart tests clearly identify the 'unaccusative' open as an accomplishment, whereas the transitive break tests as a causative accomplishment.

Middle constructions with implements are not as prevalent. Consider:

(46) a. ?This book reads easily with glasses.

b. ?This soup eats easily with a spoon.

c. ?These birds are easily watched with binoculars.

One reason for this is that base LSs of the verbs do not have the full causal structure that the ones in (45) have. As was explored in section 8.2.1, implements are licensed by the telic quale of the referent. It appears that this quale-based licensing is not readily compatible with middle constructions. It can be theorized that LSs functioning as arguments of middle constructions cannot take non-causal LS expansions like use' or be-with'. Attempts to include the latter also produces questionable results:
a. $\quad$ *This glass breaks easily with the goldfish.
b. ??be' ([[do' $(\varnothing, \varnothing)]$ CAUSE [BECOME broken' (glass)]], [easy']) $\wedge$ be-with' (goldfish, glass)
c. ??be' $\left(\left[\left[\mathbf{d o}^{\prime}(\varnothing, \varnothing)\right]\right.\right.$ CAUSE [BECOME broken' (glass)]], [easy']) ^ be-with' (goldfish, [[do' $(\varnothing, \varnothing)]$ CAUSE [BECOME broken' (glass)]])

Typical comitatives are obviously incompatible with middle constructions, as they are by definition without an instigator. Middle constructions are much less common (and acceptable) in Dutch than in English and the inclusion of an instrument is quite ungrammatical:

a. Dit glas breek-t makkelijk.

DEM glass break-PRS.3SG easily

'This glass breaks easily.' 


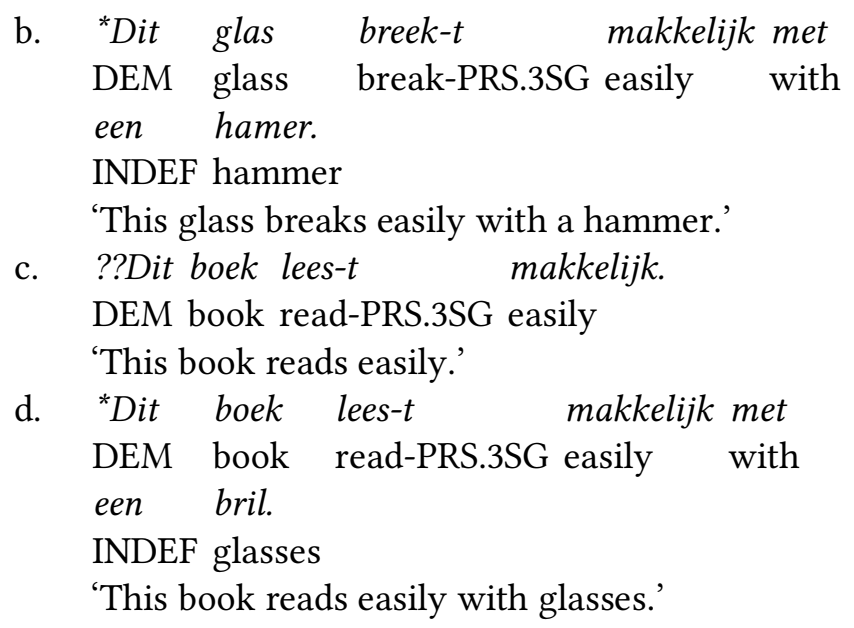

\subsection{Impossible structures}

In this section, I briefly discuss two impossible sentences featuring instruments. The reason for their impossibility is found in the logical structures, and more precisely, in violations of linking principles. Consider:

(49) a. *The key opened the door by fack. (Webb 2008: 67)

b. [do' (Jack, Ø)] CAUSE [[do' (key, Ø)] CAUSE [BECOME open' (door)]]

c. The door was opened by fack with the key.

In (49a), PSA-assignment is violated. The PSA is assigned to the instrument argument. This is only possible if the highest-ranking argument (fack) is omitted from the LS, which would constitute a case of ISA. By keeping the slot lexically filled, either it or the lowest-ranking argument can be assigned the PSA. The latter option is given in (49c). As key is neither the highest nor the lowest argument in (49a), it cannot be selected as PSA. In other words, English does not allow intermediate effectors to be selected as PSA if the instigator is lexically filled. It is true that English generally does not allow NMRs as PSA, but there are some 
varieties of English that do (Hudson 1992: 257). An example of this is given in (50e).
a. Todd gave the pad to Michael. A+PSA U NMR
b. Todd gave Michael the pad.
A + PSA
$\mathrm{U} \quad \mathrm{NMR}$
c. The pad was given to Michael by Todd. U+PSA NMR A
d. Michael was given the pad by Todd. $\mathrm{U}+\mathrm{PSA} \quad \mathrm{NMR} \quad \mathrm{A}$
e. The pad was given Michael by Todd. $\mathrm{NMR}+\mathrm{PSA} \quad \mathrm{U} \quad \mathrm{A}$

In (50c), the undergoer is assigned PSA-hood as it is the passivized version of (50a). The example in (50d) has the added complexity that it has undergone dative shift. In other words, (50d) is the passivized version of (50b), rather than of (50a). The example in (50e) is also a passivized version of (50b), but with the NMR selected as PSA. This is only possible in a subset of English varieties (Hudson 1992: 257).

Examples like the one in (51a) are ungrammatical. There are two possible (but wrong) LSs for (51a). They are given in (51b-51c).

(51) a. "The key opened the door with fack.

b. $\quad$ *[do' (Jack, Ø)] CAUSE [[do' (key, Ø)] CAUSE NMR

A [BECOME open'(door)]]

$\mathrm{U}$

c. $\quad{ }^{*}\left[\mathbf{d o}^{\prime}(\mathrm{key}, \varnothing)\right]$ CAUSE $\left[\left[\mathbf{d o}^{\prime}(\mathrm{Jack}, \varnothing)\right]\right.$ CAUSE

A NMR

[BECOME open' (door)]]

$\mathrm{U}$

The LS in (51b) is inadmissible because the AUH is violated: The intermediate argument is selected as actor, which is not allowed. In (51c), the AUH is not violated, but actionality restrictions are violated: Key is 
simply too low on the actionality scale to occupy the initial $\mathrm{x}$-argument position.

\subsection{Conclusion}

This chapter explored the linking of the concepts discussed in previous chapters. The central question of this chapter can therefore be stated in RRG-terms: How are the components in the LSs related to the constituent projection? I posited linking rules to account for instruments and causees in the same sentence. French was chosen as a language of illustration because 1) the relevant sentences are instances of nuclear cosubordination (i.e. they behave like simple sentences as far as linking is concerned) and 2) French has clear differential causee-marking, driven by differences in the strength of causation.

A proposal was also made to account for non-predicative without, which is assumed to be the marker for potential instruments, implements and the absence of an attribute. The rule governing nonpredicative without is a very specific one and could potentially conflict with the more basic with-rule. To account for the ordering of both rules, I proposed to follow the Paninian principle which states that the more specific of two rules applies in case both are possible. Predicative with and without, on the other hand, are unproblematic as the occurrence of the prepositions in the morphosyntax is explained by their predicative nature.

Furthermore, I explored some of the less typical occurrences of instruments. It was shown that passives containing instruments are captured with the same constructional schema as a normal passive (at least in English) because the instrument-effector is unaffected by the construction. The passive version of ISA, on the other hand, was captured by combining the constructional schema for ISA with the basic schema for plain passives. Middle constructions with instruments are fairly straightforward as they obey the same principles as normal middle constructions. However, it was shown that middle constructions with implements are generally disfavored. An account for the instrument unaccusative construction was provided, even though this construction is 
considered by many to be unnatural and ungrammatical. Because it receives some attention in the literature, it was investigated in this chapter. 
